\title{
Inovação na aula universitária: espaço de pesquisa, construção de conhecimento interdisciplinar, espaço de aprendizagem e tecnologias de comunicação
}

\author{
Marcos Tarciso Masetto
}

\section{Resumo}

Considerando-se o cenário de uma Sociedade do Conhecimento, este artigo procura refletir sobre as novas demandas que se propóem para a aula universitária e as possíveis inovaçóes que possam atendê-las. Trabalhamos sobre quatro demandas que entendemos sejam as mais relevantes: Aula Universitária como espaço de pesquisa, como espaço de construçáo de conhecimento interdisciplinar, como espaço de desenvolvimento de aprendizagem e como espaço e tempo de uso das tecnologias de informação e comunicação. Cada uma destas demandas foi objeto de uma análise que propiciou sugestôes de inovaçóes possíveis. O objetivo deste artigo é colocar em debate a questão de encaminhamentos concretos para que as aulas universitárias possam efetivamente ser dinamizadas com procedimentos de inovação. $\mathrm{O}$ método que usamos para elaborar o presente trabalho foi o de açáo - reflexão sobre a prática pedagógica de docentes universitários. Trabalhamos com três grupos de professores, em três áreas diferentes: engenharia, educação e odontologia. Cada um destes três grupos planejou aulas que exploraram ensino com pesquisa, conhecimento interdisciplinar e tecnologias de comunicaçáo, integrados ao processo de aprendizagem de seus alunos. Sobre esta prática desenvolveu-se uma reflexão crítica que permitiu adaptaçôes. O que neste artigo se apresentam são as conclusões a que chegamos a partir destas práticas pedagógicas e suas respectivas reflexôes. Ainda como conclusão destas interaçốes entre professores visando à inovação em aulas universitárias, pudemos observar que subliminarmente a todas as inovaçóes sugeridas encontramos como elemento fundamental e imprescindível a necessidade de se criar e sustentar entre professor e alunos uma interação pessoal entre adultos.

Palavras-chave: Aula - Inovação. Pesquisa. Tecnologia da informação e da comunicação.

* Doutor em Educação pela Pontifícia Universidade Católica de São Paulo. Professor Titular da Pontifícia Universidade Católica de São Paulo. Professor Titular da Universidade Presbiteriana Mackenzie. Professor Associado Livre Docente Aposentada da Faculdade de Educação da USP. 


\section{Introdução}

A reflexáo sobre este tema colocou-me diante de um grande desafio. Encontrava-me frente a uma trilogia: aula universitária como uma realidade centenária, uma sociedade do conhecimento com novas demandas para essa atividade docente e inovaçóes pedagógicas exigidas para a transformação das aulas. Como realizar esta triangulação?

A Sociedade do Conhecimento marcada pela diversidade de fontes produtoras de pesquisa, pelo acesso imediato e em tempo real a estas informaçóes e aos próprios pesquisadores, pela valorizaçâo e resgate do processo de aprendizagem como um contínuo desenvolvimento das pessoas e das comunidades e promotora de inovação contínua em produtos e serviços, esta sociedade em que vivemos pode nos oferecer um grande cenário que nos permita a discussáo integrada dos três aspectos mencionados.

Veen e Wrakking assim se expressam:

A sociedade do futuro exige que seus cidadáos sejam capazes de lidar com a complexidade, tanto na vida particular como na vida profissional... com problemas complexos e não muito claros a partir de ângulos diferentes, apresentando soluçôes inesperadas. Adquirir conteúdo deixará de ser a meta principal da educação, que dará mais ênfase ao que é significativo e relevante [...]. As escolas facilitaráo a aprendizagem para uma geração que sabe viver e trabalhar em organizaçôes e instituiçôes nas quais o conhecimento é intenso e onde tal geração terá de depender da flexibilidade e da adaptabilidade para lidar com condiçóes e situaçóes que estão em constante mudança. (VEEN; WRAKKING, 2009, p. 14).

Esta sociedade iluminando nossas aulas universitárias centenárias pode trazer à tona novas demandas que exigirão inovaçóes na postura do professor, no desempenho de seu papel como mediador, nos conteúdos a serem trabalhados e nas práticas pedagógicas a serem desenvolvidas com metodologias ativas voltadas para o processo de Aprendizagem na Perspectiva da Inovação (GAETA; MASETTO, 2010). 
Dentre as novas demandas que estão exigindo inovaçóes em nossas aulas universitárias, podemos destacar para nossa reflexão quatro delas: a) Aula Universitária como espaço de pesquisa; b) como espaço de construção de conhecimento interdisciplinar; c) como espaço de desenvolvimento de aprendizagem e d) como espaço e tempo de uso das tecnologias de informação e comunicação.

\section{Aula universitária como espaço de pesquisa}

Vivemos numa sociedade em que somos bombardeados continuamente por informações. Estas chegam até nós pelos diferentes meios de comunicação que acessamos diariamente: é o rádio, a televisão, são os jornais e revistas de grande circulação, os periódicos especializados, os livros publicados, a internet, os inúmeros sites, os periódicos eletrônicos, o contato direto com pesquisadores e especialistas a um leve toque de algumas teclas de nosso computador.

A quantidade imensa de dados e informaçóes produzida a cada dia e o acesso facilitado a essas fontes de informação diretamente pelo usuário retiraram do professor tanto a possibilidade de ele poder dominar todo o conhecimento hoje publicado em sua área, como o privilégio de ser o único intermediário entre a ciência e seus alunos, colocando-o como um dentre outros meios de se adquirir informaçóes.

A aula deixou de ser o espaço e o tempo de o professor transmitir as informaçóes aos alunos, e nova demanda surgiu: como trabalhar com o aluno para que ele aprenda a buscar as novas informaçôes, a estar plugado com as várias fontes de informações, como obtê-las, organizá-las, analisá-las, criticá-las, selecioná-las e integrá-las a seu mundo intelectual? Numa palavra, como aprender fazendo pesquisa? (MASETTO, 2003, 2010).

Pesquisar faz parte integrante da vida profissional nos dias de hoje. Pesquisa faz parte integrante da vida do aluno de hoje. E por isso mesmo, aprender fazendo pesquisa tornou-se uma demanda nas aulas universitárias, substituindo o modelo tradicional de transmissão e recepção de informaçóes

Não se trata mais de aprender a replicar as soluçóes dadas pelos professores aos problemas, mas de se preparar para novos desafios, problemas novos que exigem novos encaminhamentos e imaginação para soluçóes criativas. Tais habilidades e competências o formando não adquirirá com o 
modelo tradicional de aulas. Ele precisará aprender a pesquisar e se atualizar durante o curso de graduação.

Desta forma, diminuiu-se o status do professor e sua necessidade?

De forma alguma, apenas suas funçóes foram direcionadas para aquelas próprias de um formador e educador de profissionais.

O professor continua sendo uma das fontes de informação e experiências práticas para seu aluno, mas não a única. Hoje ele assume um papel muito mais importante e duradouro junto a seus alunos no que diz respeito ao conhecimento: colaborar para que o aluno aprenda a buscar informaçóes, detectar as fontes atuais destas informaçóes, dominar o caminho para acessá-las, aprender a selecioná-las, compará-las criticá-las, integrá-las a seu mundo intelectual. Numa palavra, o papel do professor é hoje muito mais complexo, mas muito mais significativo, pois pode transformar seu aluno num profissional que sempre estará atualizado, pesquisando, buscando, renovandose e revendo seus conhecimentos e práticas profissionais.

A realização de uma aula com pesquisa (MASETTO, 2010) exige uma inovação em seu conceito e nos procedimentos também. Por exemplo:

- Iniciar as atividades com uma situação-problema que deverá ser compreendida pelo aluno, que lhe permita verificar de quais informaçóes ele dispóe para resolvê-la e quais outras lhe faltam; ou com a proposição de um fenômeno a ser compreendido e explicado cientificamente.

- Sempre com orientação do professor, organizar as informaçóes que possui a respeito do problema ou do fenômeno e planejar um caminho para buscar as que lhe faltam: buscar as fontes, registrálas, estudar, documentar e fichar as informaçōes obtidas, trazê-las para a aula.

- Apresentar o resultado de sua pesquisa aos colegas, trocar as informações, discuti-las, selecioná-las, organizá-las para serem acrescentadas às outras já conhecidas.

- Procurar resolver a situação - problema ou explicar o fenômeno com as informações obtidas.

- Fazer um relatório indicando o problema, sua solução e a fundamentação teórica da mesma, ou a explicação científica do fenômeno estudado. 
- Estes procedimentos, para permitirem a aprendizagem do aluno, inclusive com relação a pesquisar, precisam se cercar de alguns cuidados: sempre o professor deverá estar presente e orientando as atividades, oferecendo feed back aos alunos enquanto trabalham, verificando se todos (e cada um) está aprendendo, trazendo materiais, realizando as tarefas combinadas, certificando-se de que as informaçóes obtidas são trocadas entre os alunos, e verificando se já são suficientes ou não, podendo-se ampliar o tempo de pesquisa.

Este ensino com pesquisa pode ser orientado para ser realizado individualmente ou em pequenos grupos. Esta segunda hipótese parece mais interessante devido à possibilidade de o aluno aprender a trabalhar em equipe, de forma colaborativa, trocando idéias e informaçóes, aprendendo a ouvir e respeitar opinióes alheias, habilidades tão importantes para o profissional de hoje.

O tema da situação problema pode ser mais complexo, trazendo para seu estudo tópicos a serem abordados por diferentes disciplinas ou assuntos que envolvem diferentes áreas de conhecimento, permitindo uma solução mais adequada e interdisciplinar, práticas profissionais novas, contatos com especialistas, entrevistas, visitas técnicas, etc.

Transformando-se a aula em espaço de pesquisa, ganha relevo a possibilidade de se explorarem os meios eletrônicos, principalmente a internet como grande recurso para se desenvolver a busca de informaçóes. $\mathrm{Na}$ verdade, quando trabalhamos somente com livros ou periódicos em bibliotecas das instituiçóes, o acesso se torna mais difícil devido à disponibilidade dessas fontes.

$\mathrm{Na}$ internet, o material de consulta encontra-se disponível a todos os alunos, mesmo àqueles que não têm computador, pois conseguem acesso a ele com grande facilidade. Importante será a atuação do professor para que os alunos aprendam a selecionar as informaçóes e utilizar os sites mais importantes para o assunto da pesquisa. 


\section{Aula universitária como espaço de construção de conhecimento interdisciplinar}

A aula no ensino superior tem a marca da disciplinaridade. A grade curricular é organizada por disciplinas justapostas, que se encontram lado a lado num mesmo semestre ou se sucedem umas às outras em semestres subsequentes ou antecedentes, mas sempre sem haver diálogo entre elas, ou até mesmo sem se conhecerem. Cada uma responde por seu programa.

O conhecimento em nossa sociedade vem sendo analisado sob dois aspectos: o primeiro diz respeito à ampliação e diversificação dos ambientes e espaços de sua produção e variedade de formas de sua socialização, incluindo velocidade, imediatismo e tempo real em sua socialização.

O segundo, ao mesmo tempo em que destaca a necessidade da especialização e continuação das pesquisas científicas em áreas específicas do conhecimento, exige uma atitude e uma postura de aproximação de áreas de conhecimento que permitam uma maior, mais profunda e mais abrangente compreensão dos fenômenos naturais, dos problemas e das situaçôes de vida da comunidade humana e busca de soluçóes. Os conhecimentos específicos e enclausurados nas suas especialidades já não são suficientes para compreender, explicitar, analisar e encaminhar muitos fenômenos atuais que afetam a humanidade.

O tipo de conhecimento hoje exigido e esperado é aquele que ultrapassa os limites de uma só área, abre-se para outras ciências e formas de conhecimento, procura integração, diálogo, complementação para melhor compreender o que está acontecendo no mundo e com a humanidade e seus fenômenos de múltipla causalidade. É neste cenário que surgem as discussôes sobre a interdisciplinaridade e construção do conhecimento interdisciplinar como uma nova demanda da aula universitária (MASETTO, 2006, 2010).

A interdisciplinaridade permite-nos esperar a produção de um conhecimento científico novo a partir de duas ou mais diferentes áreas de conhecimento que se integram para tal. Se na multi ou pluridisciplinaridade as disciplinas mantêm suas especificidades e apenas se juntam para um olhar paralelo sobre um objeto de pesquisa, na interdisciplinaridade estes olhares paralelos se integram, permitindo que um novo conhecimento se produza: um conhecimento que não se encontrava nem em uma, nem em outras disciplinas isoladamente, mas que surge pelo embate e integração de aspectos 
de ciências diversas. Trata-se de um conhecimento que só existe porque as duas ou mais áreas se encontraram e enquanto se encontraram. Não existia previamente em qualquer das áreas. Começou a existir após esta integração.

A interdisciplinaridade pode se manifestar pelo diálogo e troca de conhecimentos, de análises, de métodos entre duas ou mais disciplinas e pela transferência de métodos de uma disciplina para outra na resolução de um problema. Trata-se de outra forma de produção de conhecimento, de articulação de saberes.

A preocupação atual em torno da interdisciplinaridade como alternativa ao fazer científico disciplinar prende-se a várias situaçóes. Prende-se à percepção de que a explicação ou compreensão dos fenômenos humanos e do mundo passa por uma complexidade de que as ciências disciplinares, ou a tecnologia, mesmo em suas especialidades cada vez mais profundas e argutas, não conseguem sozinhas compreender. Prende-se ao surgimento de novas tecnologias eletrônicas que foram descobertas na busca de encaminhamento para problemas envolvendo, por exemplo, áreas de engenharia e medicina, saúde e educação, administração, economia e direito, descortinando novos horizontes de intercomunicação entre pesquisadores das mais diferentes áreas do saber e novos métodos de pesquisa. Estas situaçóes criam um impulso por atividades que superem a fragmentação do conhecimento.

A Interdisciplinaridade é uma nova modalidade de atuação científica que exige uma profunda compreensão de seu significado científico e educacional; uma abertura do docente e do pesquisador para superar um paradigma até agora profundamente enraizado em todos nós, que é o modelo disciplinar de ensino e pesquisa; exige um trabalho árduo e diário, em nossa profissão, em nossa docência, em nossas pesquisas, em nossas discussōes de reformulaçóes curriculares e em nossas reflexões, análises, debates para compreender o mundo, os homens e os fenômenos para além da disciplinaridade.

A disciplinaridade continua como base do diálogo científico, mas não poderá agora reter dentro de si toda a explicação científica da vida, do homem, da sociedade. Um novo conhecimento produzido pelo entrelaçar de diversas disciplinas é que dará conta das novas exigências da ciência. Este é o cenário que aponta para a nova demanda: a interdisciplinaridade na construção de nossas aulas, alterando seu formato disciplinar. 
Como poderíamos inovar nas aulas para responder a esta demanda?

Podemos pensar numa prática multidisciplinar, planejando atividades semestrais que envolvam professores e disciplinas que serão lecionadas para o mesmo grupo de alunos que frequentam o mesmo período. Deste planejamento, podem participar ou todas as disciplinas do semestre ou algumas delas.

Serão selecionados temas comuns que permitam pesquisas, estudos, debates, trabalhos, mesas redondas, as quais, ao mesmo tempo em que consideram as especificidades de cada disciplina, buscam também os aspectos complementares que elas apresentam para a compreensão daquele tema. Para isto poderemos usar textos de áreas diferentes de conhecimento, convidar professores de outras disciplinas para trabalharem com os alunos o mesmo tema, organizar uma mesa redonda com especialistas de várias áreas que pudessem apresentar suas visôes a respeito de um problema (estes especialistas poderiam ser docentes da própria Instituição), solicitar pesquisa dos alunos em periódicos de diversas áreas para estudar um assunto, entre outras estratégias. Pode-se pensar em monografias que explicitem os vários enfoques do estudo feito, e sua avaliação ser realizada pelos professores que participaram da atividade, sendo um mesmo trabalho com notas e conceitos para todas as disciplinas que participaram do planejamento.

$\mathrm{Na}$ construção da aula na perspectiva interdisciplinar: algo de novo deverá acontecer com relação à situação anterior de multidisciplinaridade. Trata-se da produção de um conhecimento científico novo a partir de duas ou mais áreas de conhecimento que se integram para tal. Disciplinas colocam-se em diálogo que permita uma nova visão da realidade.

Para a construção multidisciplinar ou interdisciplinar do conhecimento em aulas, o papel do professor é fundamental: há que se incentivar a comunicação e cooperação entre os professores de disciplinas diferentes para conversarem, se conhecerem, conhecerem o que ensinam e trabalham em suas aulas, discutirem aspectos que seriam mais bem aprendidos nas suas respectivas áreas se trabalhassem conjuntamente.

Sem dúvida, muito se facilitaria esta atividade se o próprio currículo fosse organizado com esta preocupação interdisciplinar, privilegiando a integração das disciplinas seja daquelas que se ministram no mesmo semestre, seja daquelas que se ministram em semestres subsequentes. 
Outra alternativa curricular para facilitar a interdisciplinaridade seria se o currículo privilegiasse o desenvolvimento dos conhecimentos através de grandes temas ou problemas que envolvessem conteúdos de diversas disciplinas e cujo aprofundamento se pudesse fazer com a participação de diferentes áreas do conhecimento. Há vários modelos curriculares que atualmente estão optando por esta proposta. $\mathrm{O}$ currículo de formação do médico da Universidade Mc Master (Canadá) e o Problem Based Learning (PBL) ou Aprendizagem Baseada em Problemas (ABP) (Mastrich), Universidade Estadual de Londrina, são apenas dois exemplos, talvez os primeiros que entraram por este caminho. Hoje são várias as propostas. Trabalhar com problemas em aula poderia se constituir como uma inovaçáo para que o aluno aprendesse a construir um conhecimento interdisciplinar.

A título de exemplo, consideremos este problema: $\mathrm{O}$ governo se propóe a oferecer uma cesta básica para alimentar as famílias de baixa renda. Como deveria ser composta?

A soluçâo deste problema exige um estudo que envolve debate entre vários especialistas para the propor uma solução adequada. Será necessário um estudo de vitaminas, proteínas e carboidratos indispensáveis para a alimentação saudável das pessoas, em idades diferentes (crianças, jovens e adultos), e que náo dispóem de recursos econômicos para fazer frente a essas despesas. Precisamos das informaçóes dos especialistas em ciências, nutrição, gastronomia e economia, que, juntos, encontrem uma soluçáo para o problema, que seja nova e possivelmente diferente daquela que cada um individualmente pudesse apresentar. Uma proposta nestes termos certamente nos remeteria para uma perspectiva interdisciplinar.

Vamos a um exemplo na área da odontologia: para descobrir a melhor resina para oclusão de uma cárie e que seja possível de ser usada nos postos de saúde, no Sistema Único de Saúde (SUS), nos consultórios populares não serão suficientes apenas os avanços da tecnologia. Sem dúvida, os estudos e pesquisas em dentística são necessários, imprescindíveis mesmo, mas sem apoio de conhecimentos de economia, educação, sociologia e antropologia não se conseguirá a solução desejada, pois o problema da cárie, sua prevenção, sua oclusão quando já existe, e a promoção da saúde bucal exigem conhecimento e prática das ciências acima indicadas, cujos profissionais trabalhando e pesquisando conjuntamente encontrem 
caminhos para se resolver o problema da saúde bucal diferente daquele que cada um deles em separado indicaria.

Em ambientes profissionais, onde a realidade com sua complexidade e emergências nos surpreende a cada dia, encontramos inúmeras oportunidades de vivenciar esta interdisciplinaridade. Imaginemos um problema vital e corriqueiro como seja a necessidade de uma população ter acesso à água potável. Há uma série de decisóes tecnológicas a ser tomadas, relacionadas com a origem da água, sua coleta, seu tratamento, sua distribuição através de dutos e caixas d'água, a chegada aos consumidores em suas residências e demais logradouros públicos, o uso ou não de filtros, o uso da água fervida, a diferenciação da água conforme necessidade versus desperdício de água, custo da água para o consumidor, e outros aspectos mais.

Já pensamos quantas áreas de conhecimento deverão ser acionadas para que, trabalhando em conjunto, se possa encaminhar o problema acima? Percebemos que só por meio de uma solução que envolva todas elas e de forma integrada, se poderá encaminhar o problema? Não adianta que cada área dê sua solução específica. Elas podem até ser parcialmente contraditórias. Como integrá-las para uma saída adequada? Nesta altura dos estudos podemos encontrar uma solução interdisciplinar.

\section{Aula Universitária como espaço de desenvolvimento de aprendizagem}

As aulas planejadas e realizadas dentro de um esquema de cursos de graduação caracterizam - se por instruir, ensinar, transmitir informaçóes e experiências e deixaram na obscuridade seu aspecto fundamental, que é a aprendizagem dos alunos. Hoje, considerando a formação de profissionais, este aspecto além de ser resgatado e recolocado em seu devido lugar, tem sua concepção aprofundada e ampliada.

Entende-se hoje por processo de aprendizagem um processo de crescimento e desenvolvimento de uma pessoa em sua totalidade, abarcando minimamente quatro grandes áreas: a do conhecimento, a do afetivoemocional, a de habilidades e a de atitudes ou valores (SACRISTÁN; PEREZ GOMES, 1996; POZO, 2002; MASETTO, 2003, 2010; CLAXTON, 2005). 
A aprendizagem na área do conhecimento compreende o desenvolvimento intelectual do homem em todas as suas operaçóes mentais: capacidade de pensar, refletir, analisar, comparar, criticar, justificar, argumentar, inferir conclusóes, generalizar, buscar e processar informaçóes, compará-las, criticá-las, organizá-las, produzir conhecimentos, descobrir, pesquisar, criar, inventar, imaginar. São aprendizagens mais complexas do que apenas receber informações e reproduzi-las

Por desenvolvimento afetivo-emocional entende-se o contínuo e crescente conhecimento que o aluno deverá adquirir de si mesmo, dos diferentes recursos que possui, dos seus limites, das potencialidades a serem otimizadas. Diz respeito ao desenvolvimento de sua autoestima e ao relacionamento com as pessoas do grupo, incluindo colegas e o próprio professor, ao clima de confiança a ser criado em aula, ao espírito de solidariedade, cooperação, respeito, diálogo a ser construído entre os participantes do processo de aprendizagem.

\section{$\mathbf{O}$ desenvolvimento na área de habilidades humanas e profissionais} significa aprender o que podemos fazer com os conhecimentos adquiridos: aplicá-los, resolver problemas, criar novas soluçóes, usá-los em situaçóes novas e diferentes daquelas onde os aprendemos, aperfeiçoar e desenvolver técnicas, instrumentos e procedimentos.

\section{A consideraçáo do desenvolvimento de atitudes e valores coloca-} nos no aspecto mais delicado da aprendizagem de um profissional. É razoavelmente claro para o professor que suas aulas deverão permitir que o profissional ali formado tenha condiçóes de responder com competência pelas soluçóes tecnologicamente corretas aos problemas e desafios profissionais que se lhe apresentarem em seu trabalho. $\mathrm{O}$ que não é tão claro para este mesmo professor é que em cada decisão tecnológica que um profissional toma há nela embutidas consequências que afetam pessoas, grupos humanos, meio ambiente, cultura, política, saúde, educação, cidades, naçóes, que precisam ser analisadas e discutidas antes que a solução tecnológica seja assumida.

A responsabilidade social hoje é uma exigência de toda a sociedade para com seus profissionais, assim como um comportamento ético. Estamos no terreno das atitudes e valores que são o coração do processo de aprendizagem e que é necessário que os aprendamos, inclusive em nossas aulas. 
Outro aspecto envolvendo o conceito de aprendizagem muito debatido e estudado nos nossos dias é sua qualificação como aprendizagem significativa. No dizer de Sacristán e Pérez Gómes, comentando Ausubel:

A aprendizagem significativa, seja por recepçáo, seja por descoberta, se opóe a aprendizado mecânico, repetitivo e memorístico. Compreende a aquisição de novos significados... A essência da aprendizagem significativa está em que as idéias expressas simbolicamente se relacionam de maneira não arbitrária, mas substancial com o que o aluno já sabe. O material que aprende é potencialmente significativo para ele. (SACRISTÁN; PEREZ GOMES, 1996, p. 46).

Entendemos por aprendizagem significativa aquela que envolve o aluno como pessoa, como um todo (idéias, sentimentos, cultura, valores, sociedade, profissão). Ela se dá quando o que se propóe para aprender relaciona-se com o universo de conhecimento, experiências e vivências do aprendiz, como já vimos acima; permite a formulação de perguntas e questóes que de algum modo o interessem e o envolvam ou lhe digam respeito; permite-lhe entrar em confronto experimental com problemas práticos de natureza social, ética, profissional que lhe são relevantes; permite e ajuda a transferir o aprendizado da universidade para outras circunstâncias da vida; suscita modificaçôes no comportamento e até mesmo na responsabilidade do aprendiz.

Esta demanda para a aula universitária vai exigir inovaçóes no que diz respeito a planejar aulas voltadas para que o aluno possa desenvolver os vários aspectos da aprendizagem e não apenas os cognitivos. Este aspecto de inovação tem por base uma mudança radical por parte do professor na compreensáo de seu papel e na postura a assumir em aula, o que o coloca como mediador de aprendizagem para seu aluno e não apenas como expert em um assunto que vai transmitir a eles. É preciso ter uma postura de trabalho em equipe com seus alunos, de parceria nas atividades e de coresponsabilidade pelo processo de aprendizagem.

A partir desta mudança por parte dos docentes, entáo podemos pensar em implantar algumas inovaçóes para responder a esta demanda das aulas, tais como: a) alterar o planejamento para que durante o 
tempo dedicado a cada disciplina o aluno aprenda a pesquisar e buscar informaçôes, compará-las e integrá-las, exercitando a crítica sobre elas; b) desenvolver sua capacidade de pensar, de raciocinar, de fazer inferências e generalizaçóes, de analisar as informaçóes e de produzir um conhecimento.

O uso de dinâmicas de grupo variadas pode contribuir muito para que o aluno aprenda a conhecer suas potencialidades e deficiências, seus limites e capacidade de superação, seus erros e possibilidades de aprender; a desenvolver confiança no professor e nos seus colegas que lhe permitam superar suas inseguranças e desenvolver sua autoestima (TORRE, 2008)

É preciso planejar a aula de forma tal que os alunos explorem as aplicaçóes e usos de seus conhecimentos em sua realidade profissional. Até hoje, estágios e visitas técnicas ainda são usadas para esta aprendizagem. Mas suas realizações podem ser bem modificadas, por exemplo, com a valorização do estágio como eixo curricular (cursos cooperativos) (MASETTO, 2007), pelo envolvimento no planejamento e realização do estágio por parte das instituiçóes educacionais e profissionais para as quais interessa o estágio como possibilidade de intercâmbio entre elas e de atualização profissional e curricular. A valorização do estágio e seu repensar partem de uma mudança de atitude da universidade para com as instituiçōes ou organizaçóes onde os estágios serão realizados.

Deve-se reconhecer o grande potencial do estágio como excelente espaço de aprendizagem profissional, selecionar os locais onde deve acontecer, com os níveis desejados - desde o mais simples até o mais complexo, integrar o estágio no currículo, planejando para que suas atividades sejam discutidas dentro de todas as disciplinas do currículo, e não apenas nas disciplinas de práticas de estágio, ocorrendo ao longo de todo o curso.

É importante valorizar para os professores e para os alunos este tipo de aprendizagem, conferindo-lhes igual ou até maior valor do que às aulas teóricas, acompanhando os estagiários e oferecendo-lhes subsídios necessários por professores da instituição ou profissionais dos locais do estágio.

É necessário interagir com as instituições de estágio em sua seleção, na discussão do projeto pedagógico de formação dos profissionais, deixando bem claro quais as necessidades de aprendizagem dos alunos nessa instituição, para envolvê-las com uma formação que prepare os profissionais para 
interagir com os alunos, ajudando-os a perceber que o estágio é também para eles uma oportunidade de se relacionarem com a universidade e darem continuidade a sua formação profissional.

Por fim, importa dizer às instituições que, ao realizar os estágios elas não só estão colaborando com a formação daqueles profissionais, como também poderão estar se beneficiando com a participação desses alunos e professores da universidade.

Nesse processo, pode-se fazer um levantamento sobre novos espaços e oportunidades de estágios, novos tipos de exercício das profissóes, novos mercados de trabalho, ou seja, valorizar o estágio, as visitas técnicas, escritórios modelos ou empresas juniores como excelentes espaços de aprendizagem para o aluno, atribuindo-lhe a importância que se atribui às aulas teóricas. Por fim, compreendê-los como importante atividade de docência, também esta equiparada às atividades de ministrar aulas.

Planejar a aprendizagem de atitudes e valores significa trabalhar com estudo de casos reais ou simulados que contenham embutidos os valores a serem discutidos por ocasião de tomada de decisão tecnológica. Em todas as decisóes profissionais há valores incluídos: valores éticos, culturais, antropológicos, políticos, ambientais, com consequências para pessoas, comunidades ou meio ambiente.

Há necessidade de se criarem condiçóes para que os alunos aprendam a enxergá-las, discuti-las e analisá-las. A aula é um espaço importante e fundamental de credibilidade para que o aluno, juntamente com seu professor, interesse-se em analisar estes valores, discuti-los e tomar posição competente e cidadã em suas decisóes profissionais.

Para responder à demanda atual para a aula universitária, no sentido de que ela seja um espaço para o desenvolvimento da aprendizagem dos alunos, é comum encontrarmos certas resistências por parte dos professores, quase sempre devido a um cronograma de aulas que mal permite cumprir o programa conteudístico da disciplina. De fato, há certa dificuldade de se pensar em inovaçóes para responder às demandas das aulas no ensino superior se nos mantivermos fixados nos 50 ou 100 minutos de aula. Uma inovação no planejamento desse tempo pode apresentar uma solução: o planejamento por unidades de aprendizagem. 
Entendemos por unidade de aprendizagem o estabelecimento de um prazo de tempo que permita o alcance de determinados objetivos de formação profissional, trabalhando-se com as informações necessárias, utilizando-se estratégias que facilitem o alcance dos objetivos e a realização de um processo de avaliação que demonstre a aprendizagem adquirida. A realização integrada deste conjunto vai exigir um tempo maior que os 50 minutos de uma aula e será determinada pelos objetivos de aprendizagem conforme definidos acima, isto é, um conteúdo planejado por grandes temas integradores de vários pontos do programa da disciplina, seguido de estratégias que permitam o uso de tempos e espaços fora de sala de aula. Tal unidade comportará um conjunto de aulas que serão necessárias para sua realização completa. Contará com duas ou três semanas de trabalho, dependendo do número de aulas semanais e da complexidade dos objetivos a serem estipulados.

Nas experiências que conhecemos, o semestre letivo é trabalhado através de cinco ou seis unidades, pelas quais se distribuem os objetivos alcançados; os conteúdos programáticos são organizados e absorvidos por cinco ou seis grandes temas integradores; conta-se com tempo e espaço para atividades no período das aulas; e fora delas para a preparação ou aplicação da matéria estudada, além da realização de uma avaliação permanente e formativa.

\section{Aula universitária como espaço e tempo de uso das tecnologias de informação e comunicação}

$\mathrm{Na}$ abordagem deste tema, encontramo-nos diante de uma série de desafios. Se olharmos os alunos que estamos recebendo no ensino superior, imediatamente perceberemos que se trata de jovens que cresceram com a tecnologia fazendo parte de sua vida desde a infância: controle remoto, mouse, minidisc, telefone celular com todo o conjunto de recursos eletrônicos que ele engloba, iPod, iPhone, mp3, etc, Tais recursos permitem ao jovem estar continuamente conectado com informaçóes, controlar seu fluxo, lidar com informações descontínuas e simultâneas. Este jovem chega ao ensino superior acostumado com a sobrecarga de informaçóes, mas ao mesmo tempo com dificuldade para criticar e selecionar aquelas que de fato lhe interessam. 
Em “Homo zappiens” Veen e Vrakking descrevem este jovem como:

Homo zappiens é um processador ativo de informação, resolve problemas de modo muito hábil, usando estratégias de jogo, e sabe se comunicar muito bem. Sua relação com a escola mudou profundamente, pois esta, embora ocupando em termos de horas grande parte de seu dia, é apenas mais um ponto de interesse, entre outros mais interessantes como as redes de amigos, seus trabalhos de meio-turno e os encontros de final de semana [...]. O homo zappiens aprende por meio de brincar e das atividades de investigação e descoberta relacionadas ao brincar. Sua aprendizagem começa táo logo ele jogue no computador, e a aprendizagem logo se torna uma atividade coletiva, uma vez que os problemas serão resolvidos de maneira coletiva e criativa em uma comunidade global. (VEEN; VRAKKING, 2009, p. 12).

O surgimento da informática e da telemática trouxe inúmeras oportunidades aos usuários, aos alunos e professores para entrar em contato com as mais novas e recentes informaçóes, pesquisas e produçóes científicas do mundo em todas as áreas. Trouxe oportunidade de desenvolver a autoaprendizagem e a interaprendizagem à distância, a partir dos computadores que se encontram nas bibliotecas, nas residências, nos escritórios, em locais de trabalho.

Surgem novas formas para se construir o conhecimento e produzir trabalhos monográficos e relatórios científicos; oportunidade de se integrar movimento, luz, som, imagem, filme, vídeo e texto em novas apresentaçóes de resultados de pesquisa e de assuntos e temas para as aulas.

Dinamiza-se a possibilidade de orientar os alunos em suas atividades não apenas nos momentos de aula, mas nos períodos “entre-aulas" também; oportunidade de desenvolver criticidade diante de tudo o que se vivencia através do computador, curiosidade para buscar coisas novas, criatividade para se expressar e refletir, ética para discutir os valores contemporâneos e os emergentes em nossa sociedade e em nossa profissão.

Criou-se uma nova demanda para as aulas universitárias: o uso das tecnologias de informação e comunicaçáo (TICs) em sua realização. Por TICs 
queremos entender o uso da informática, do computador, da internet, do CD Rom, da hipermídia, da multimídia, de ferramentas para a educação à distância como chat, grupos ou lista de discussão, correio eletrônico, etc. e de outros recursos e linguagens digitais de que atualmente dispomos e que podem colaborar significativamente para tornar o processo de educação mais eficiente e mais eficaz.

Tais recursos e técnicas cooperam para o desenvolvimento da educação em sua forma presencial (fisicamente), uma vez que podemos usá-los para dinamizar nossas aulas em cursos presenciais, tornando-os mais vivos, interessantes, e mais vinculados com a nova realidade de estudo, de pesquisa e de contato com os conhecimentos produzidos. Cooperam também e, principalmente, para o processo de aprendizagem à distância (virtual), uma vez que foram criadas para atendimento desta nova necessidade e modalidade de formação. Exploram o uso de imagem, som, movimento simultâneo, a máxima velocidade no atendimento às nossas demandas, e o trabalho com as informaçóes dos acontecimentos em tempo real. Exploram as variáveis tempo e espaço, tornando-as condiçóes muito favoráveis para a aprendizagem: quando estudar, como estudar, como aprender, como se comunicar, quando se comunicar, como registrar e documentar.

As TICs colocam professores e alunos trabalhando e aprendendo à distância, dialogando, discutindo, pesquisando, perguntando, respondendo, comunicando informaçóes através de recursos que permitem a estes interlocutores, vivendo nos mais longínquos lugares, se encontrarem e se enriquecerem com contatos mútuos. Professores especialistas, grandes autores e pesquisadores que para muitos seriam inacessíveis, através destes recursos agora podem com eles interagir.

Tal demanda que inovaçóes pode provocar nas aulas?

Instituições de Ensino Superior têm que responder a esta nossa pergunta de uma maneira muito rápida e imediata: a construção de um laboratório de informática atualizado, com número de computadores conveniente para o número de alunos, com os sites de pesquisa e busca de informaçóes de todas as disciplinas implantados, com biblioteca informatizada e um sistema de ensino tipo moodle instalado Assim, estaremos com inovação adequada para responder à demanda de uma aula universitária como espaço de tecnologias de informação e comunicação. Entendemos 
que uma tal infraestrutura se faz necessária e imprescindível para que algo de diferente e inovador aconteça nessa área de tecnologia de informação e comunicação. Mas, só a infraestrutura não é suficiente para a inovação que se espera.

Pensa-se, por exemplo, em:

- organização de teleconferências com participação direta e imediata dos alunos e do professor em debate com o conferencista;

- organização de banco de dados que sirvam para incentivar e orientar os alunos no levantamento de informaçóes das várias disciplinas para posterior aprofundamento, análise crítica e construção do conhecimento;

- no uso das TICs, centrar-se no aluno e em sua aprendizagem e no processo da interaprendizagem, incentivando a aprendizagem ativa e colaborativa, facilitando a atitude de mediação do professor e o desenvolvimento da relação de parceria e colaboração entre professor - aluno, aluno-aluno e entre os grupos;

- professor e aluno passam a trabalhar conjuntamente não só na aula, quando se encontram fisicamente, mas também à distância, em suas residências, no período entre uma aula e outra, dialogando, discutindo, pesquisando, perguntando, respondendo, comunicando informaçóes;

- o mesmo se diga com relação aos colegas de turma ou de classe: pensemos nestas pessoas debatendo, discutindo, apresentando suas ideias, colaborando para a compreensão de um tema e vivendo em lugares diferentes, com experiências, culturas, valores, costumes totalmente diferentes.

- com o uso destas tecnologias, o conteúdo poderá estar mais disponivel aos alunos, facilitando as pesquisas e buscas, desafiando e provocando a curiosidade.

- o uso do portfólio, bem como a constante comunicação entre professor e alunos permitirá a criação de um sistema de avaliação permanente, que se constituirá como um grande fator de aprendizagem para os alunos.

Estas são algumas das características fundamentais para se poder falar em inovações nas aulas universitárias num mundo do "homo zappiens" 
(CEBRIAN, 2003). Tais inovações irão exigir que os professores revejam com seriedade suas competências quanto a alguns aspectos, como por exemplo:

a) o domínio e uso dessas técnicas e do ambiente virtual;

b) o domínio dos aspectos pedagógicos de planejamento e dos demais que facilitam a aprendizagem;

c) a criação de um ambiente virtual amigável e colaborativo desde a apresentação inicial, realização de um primeiro encontro pela internet, discussão de contrato psicológico e criação de uma comunidade;

d) a competência gerencial para planejar e acompanhar a realização do planejamento quanto aos objetivos propostos, agendamento do curso, ritmo do mesmo, materiais disponibilizados, avaliação dos trabalhos com feed back, e uso do portfólio individual e de grupo.

O professor precisa hoje adquirir a competência da gestão dos tempos à distância combinado com o presencial. Gerir o que vale a pena fazer pela Internet, que ajuda a melhorar a aprendizagem, que mantém a motivaçáo, que traz novas experiências para a turma, que enriquece o repertório do grupo.

Os ambientes virtuais aqui complementam o que fazemos na sala de aula. O professor e os alunos são «libertados» de algumas aulas presenciais e precisam aprender a gerir classes virtuais, a organizar actividades que se encaixem em cada momento do processo e que dialoguem e complementem o que estamos a fazer na sala de aula. (MORAN, 2005, p. 79).

\section{Para concluir estas reflexões}

Quando analisamos as demandas que hoje a aula universitária nos propóe e as inovaçóes que se podem implementar como resposta a elas, observamos que, subliminarmente a todas as inovaçóes sugeridas, 
encontramos como elemento fundamental e imprescindível a necessidade de se criar e sustentar entre professor e alunos uma interação pessoal entre adultos (MASETTO, 2003, 2010; ZABALZA, 2004, 2006).

Esta relação entre adultos significa da parte do professor que ele acredite que o aluno é capaz de aprender e de assumir responsabilidade por seu processo de aprendizagem; que é capaz de ser parceiro na construção de sua formação profissional; e que é capaz de responder pelas consequências desta construção (confiança no aprendiz). Significa que o professor se coloque no lugar do aluno para poder compreender melhor suas necessidades, seus problemas e dificuldades, sua desmotivação e desinteresse, para poder interagir mais adequadamente com ele (empatia).

Tal disposição abre o professor para o respeito ao aluno, para o diálogo, para a disponibilidade em ajudar o aluno a superar as dificuldades e aprender, para assumir uma atitude de mediação pedagógica que, ao mesmo tempo em que se dispóe a ajudar, está solícito também para exigir a realização das atividades programadas. Disposição para chamar o aluno à participação para trabalhar junto com os colegas, em parceria e corresponsabilidade pelo processo de formação.

Esta relação entre adultos significa da parte do aluno assumir atitude de participação ativa no processo de aprendizagem, de acordar com o professor a construção de um processo de aprendizagem no qual ele terá parte ativa e de sujeito, ou seja, de agente principal juntamente com o professor, de responder responsavelmente pela sua parte no processo e de assumir as consequências deste acordo, de assumir a parceria de trabalho com o professor e os colegas, e por isso mesmo desenvolver atitudes de respeito e de diálogo com estes personagens como parceiros no processo.

Sem dúvida, tal inovação de relaçóes entre professor e alunos demandará iniciativa do professor nos primeiros dias de aula, desde a reorganizaçáo do espaço físico da sala até a combinação sobre um programa de trabalho na disciplina, em que seus diversos aspectos envolvendo os objetivos a serem aprendidos, os temas a serem estudados, os autores a serem trabalhados, a metodologia a ser empregada nas aulas e o processo de avaliação a ser realizado sejam discutidos e acordados.

Este realmente poderá se constituir em um início de curso inovador frente às demandas atuais das aulas universitárias, que terá seu 
prosseguimento com as sugestóes apresentadas neste artigo e outras que serão criadas e inventadas pelos docentes preocupados em construir uma docência no ensino superior que seja competente, atual e profissional.

\section{REFERÊNCIAS}

CEBRIAN, Manuel (Coord.). Enseñanza virtual para la innovación universitaria. Madrid: Narcea, 2003.

CLAXTON, Guy. O desafio de aprender ao longo da vida. Porto Alegre: Artmed, 2005.

GAETA, Cecília; MASETTO, Marcos. Metodologias ativas e o processo de aprendizagem na perspectiva da inovação. In: CONGRESSO INTERNACIONAL PBL, 2010, São Paulo. Anais... São Paulo: USP Leste, 2010.

MASETTO, Marcos Tarciso. Competência pedagógica do professor universitário. São Paulo: Summus, 2003.

MASETTO, Marcos Tarciso. O Professor na hora da verdade. São Paulo: Avercamp, 2010.

MASETTO, Marcos Tarciso. Um paradigma interdisciplinar para a formação do cirurgiấo dentista. In: CARVALHO, Antonio Cesar Perri de; KRIGER, Leo. Educação Odontológica. São Paulo: Artes Médicas, 2006.

MASETTO, Marcos Tarciso (Org.). Ensino de engenharia: técnicas para otimização das Aulas. São Paulo: Avercamp, 2007.

MORAN, José Manuel. A Pedagogia e a didáctica da educação online. In: SILVA, Ricardo Vidigal da; SILVA, Anabela Vidigal da (Org.). Educação, aprendizagem e tecnologia: um paradigma para professores do século XXI. Lisboa: Silabo, 2005.

POZO, Juan Ignácio. Aprendizes e mestres: a nova cultura da aprendizagem. Porto Alegre: ArtMed, 2002.

SACRISTÁN, Gimeno J.; PÉREZ GOMES, A. I. Compreender y transformar la enseñanza. Madrid: Morata, 1996. 
TORRE, Saturnino de la (Dir.). Estrategias didacticas em el aula: buscando la calidad y la innovación. Madrid: UNED, 2008.

ZABALZA, Miguel A. O ensino universitário: seu cenário e seus protagonistas. Porto Alegre: ArtMed, 2004.

ZABALZA, Miguel A. Competências docentes del profesorado universitário: calidad y desarrollo profesional. Madrid: Narcea, 2006.

VEEN, Win; VRAKKING, Bem. Homo zappiens: educando na era digital. Porto Alegre: ArtMed, 2009. 
Innovation in the university classroom: research, interdisciplinary knowledge construction, learning development, and communication technologies

\section{Abstract}

Taking into consideration the scenario of a Society of Knowledge, this article aims at reflecting on the new demands and the possible innovations of university lessons. We worked on four demands which we considered the most relevant ones: university lessons as room for research, interdisciplinary knowledge construction, learning development, and space and time for the use of communication and information technology. Each of the four demands was analyzed and provided suggestions for possible innovations. The purpose of this article is to put under discussion the idea of taking concrete actions in order to dynamize university lessons by adopting concrete procedures of innovation. The method used was action-reflection on the pedagogical practice of university professors. We work with three groups of professors, from three different areas: engineering, education, and dentistry. Each of these three groups planned lessons which focused on research, interdisciplinary knowledge, and communication technology integrated to the learning processes of their students' learning. Critical reflection on such practice allowed
Innovación en el aula universitaria: construcción de espacios de investigación conocimento interdisciplnario, area de las tecnologías de aprendizaje y comunicación

\section{Resumen}

Teniendo en cuenta el escenario de una sociedad del conocimiento, este trabajo discute las nuevas demandas que se proponen para las aulas universitarias y las posibles innovaciones que pueden hacerles frente. Trabajamos en cuatro demandas que creemos son los más relevantes: la Universidad de conferencia y de investigación espacial como un espacio para la construcción de conocimiento interdisciplinario como espacio para el aprendizaje y el desarrollo del espacio y del tiempo como el uso de tecnologías de información y comunicación. Cada una de estas demandas ha sido objeto de un análisis que hicieron sugerencias para posibles innovaciones. En este artículo se pone en debatela cuestión de las referencias reales a las clases de la universidad puede ser racionalizado los procedimientos de manera efectiva con la innovación de concreto. El método que usamos para llegar a este resultado es la acción reflexión sobre la práctica pedagógica de los académicos. Trabajo con tres grupos de profesores en tres áreas diferentes: la ingeniería, la educación y la odontología. Cada uno de estos tres grupos previstos lecciones que exploran con la enseñanza 
some adjustments. This article presents the conclusions we draw on those pedagogical practices and the reflections on them. Moreover, as a conclusion of the interactions among professors with a view to innovating university lessons, we could notice that subliminarlly to all suggested innovations there is the need to create and maintain a personal and adult professor-student interaction as fundamental and indispensable element. In such a broad scenario, the demands and suggestions for innovation of university lessons open room for a dialogue on the proposed theme, which, we wish, could be analyzed and enriched by our readers.

Keywords: Lesson-Innovation. Research. Communication and Information Technology. de las tecnologías de investigación, el conocimiento interdisciplinario y la comunicación integrada en el proceso de aprendizaje de sus alumnos. Acerca de esta práctica se convirtió en una reflexión crítica que permite ajustes.

Lo que se presenta en este artículo son las conclusiones que sacamos de estas prácticas de enseñanza y sus reflexiones. A pesar de que una conclusión de estas interacciones entre los profesores que buscan la innovación en las clases de la universidad se observó que subliminalmente sugirió a todas las innovaciones que encontramos fundamental y esencial como la necesidad de desarrollar y apoyar entre el profesor y los estudiantes una interacción personal entre los adultos.

Sin duda, con un telón de fondo de tal magnitud, las demandas de las aulas universitarias y sugerencias para la innovación se pone como una apertura para el diálogo sobre el tema propuesto, que están a la espera analizada y enriquecida con la participación de nuestros lectores.

Palabras clave: Conferencia Innovación. Búsqueda. Tecnología de la información y la comunicación.

\section{Marcos Tarciso Masetto}

Endereço: Rua Apinagés, 711, Apto. 141, Cep 05017-000, Perdizes, São Paulo, SP. E-mail: mmasetto@gmail.com

Recebido em: 27/5/2010

Versão final recebida em: 22/10/2011

Aprovado em: 31/10/2011 